\title{
The present and future of cardiac arrest care : international experts reach out to caregivers and healthcare authorities
}

\section{Nolan, Jerry P.}

2018-06

Nolan , J P , Berg , R A , Callaway , C W , Morrison , L J , Nadkarni , V , Perkins , G D , Sandroni , C , Skrifvars , M B , Soar , J , Sunde , K \& Cariou , A 2018 , ' The present and future of cardiac arrest care : international experts reach out to caregivers and healthcare authorities ' , Intensive Care Medicine , vol. 44 , no. 6 , pp. 823-832 . https://doi.org/10.1007/s00134-018-5230-9

http://hdl.handle.net/10138/303659

https://doi.org/10.1007/s00134-018-5230-9

publishedVersion

Downloaded from Helda, University of Helsinki institutional repository.

This is an electronic reprint of the original article.

This reprint may differ from the original in pagination and typographic detail.

Please cite the original version. 


\title{
The present and future of cardiac
} arrest care: international experts reach out to caregivers and healthcare authorities

\author{
Jerry P. Nolan ${ }^{1,2^{*}}$ (D, Robert A. Berg ${ }^{3,4}$, Clifton W. Callaway ${ }^{5}$, Laurie J. Morrison ${ }^{6}$, Vinay Nadkarni ${ }^{7}$, Gavin D. Perkins ${ }^{8}$, \\ Claudio Sandroni ${ }^{9}$, Markus B. Skrifvars ${ }^{10}$, Jasmeet Soar ${ }^{11}$, Kjetil Sunde ${ }^{12}$ and Alain Cariou ${ }^{13,14}$
}

(c) 2018 Springer-Verlag GmbH Germany, part of Springer Nature and ESICM

\begin{abstract}
Purpose: The purpose of this review is to describe the epidemiology of out-of-hospital cardiac arrest (OHCA), disparities in organisation and outcome, recent advances in treatment and ongoing controversies. We also outline the standard of care that should be provided by the critical care specialist and propose future directions for cardiac arrest research.

Methods: Narrative review with contributions from international resuscitation experts.

Results: Although it is recognised that survival rates from OHCA are increasing there is considerable scope for improvement and many countries have implemented national strategies in an attempt to achieve this goal. More resources are required to enable high-quality randomised trials in resuscitation.

Conclusions: Increasing international collaboration should facilitate resuscitation research and knowledge translation. The International Liaison Committee on Resuscitation (ILCOR) has adopted a continuous evidence review process, which facilitate the implementation of resuscitation interventions proven to improve patient outcomes.
\end{abstract}

Keywords: Cardiopulmonary resuscitation, Cardiac arrest, Post-resuscitation care, Prognostication

\section{Introduction}

Survival to hospital discharge rates following out-of-hospital cardiac arrest (OHCA) are increasing but remain in the range of $8-10 \%$ in many parts of the world. Higher survival rates are achieved in some centres that have optimised their local chain of survival. Strategies to increase rates of bystander CPR, increase the availability of public access automated defibrillators (AEDs), and to implement regional cardiac arrest networks will require collaboration with, and the engagement of, stakeholders. This review describes the epidemiology of OHCA, disparities in organisation and outcome, recent advances

\footnotetext{
${ }^{*}$ Correspondence: jerry.nolan@nhs.net

${ }^{1}$ Bristol Medical School, University of Bristol, Bristol, UK

Full author information is available at the end of the article
}

in treatment and ongoing controversies. We outline the standard of care that should be provided by the critical care specialist and propose future directions for cardiac arrest research.

\section{Cardiac arrest: epidemiology and general trends}

Incidence and survival from OHCA varies considerably both between countries and within countries. The EuReCa ONE study of 10,672 OHCAs in 27 European countries during October 2014 reported an incidence of emergency medical services (EMS)-treated OHCA of 19.0-104.0 per 100,000 people per year, and an overall survival to hospital discharge of $10.3 \%$ [1]. The North American Resuscitation Outcomes Consortium (ROC) reported an incidence of EMS-treated OHCA of 73.0 (95\% CI 71.2-74.7) per 100,000 adults per year in 2014/2015 with an overall survival to hospital discharge

\section{实 Springer}


of 11.4\% (95\% CI 10.4-12.4\%) [2]. EMS-treated cardiac arrests account for about half of the OHCA attended by and assessed by EMS at ROC sites [3]. The US Cardiac Arrest Registry to Enhance Survival (CARES) database of 132 US counties reported widely variable survival to hospital discharge rates of 3.4-22.0\% [4]. Some of these differences can be attributed to differences in healthcare systems, the quality of the local chain of survival, patient factors, and differences in how OHCA data are collected and reported. The recognition that there is potential to save many more lives from cardiac arrest has led in some countries to national strategies to improve outcome from OHCA $[5,6]$.

Studies suggest that care and outcomes after OHCA are improving. In Denmark, the incidence of EMStreated OHCA from a primary cardiac cause decreased from 40 to 34 per 100,000 people, and 30-day survival increased from 3.5 to $10.8 \%$ between 2001 and 2010 [7]. This improvement was associated with an increase in bystander CPR rates. Between 2001 and 2012, the Danish rate of bystander CPR among 30-day survivors increased from 66.6 to $80.6 \%(P<0.0001)$, and the rate of bystander defibrillation among 30-day survivors increased from 2.1 to $16.8 \%(P<0.0001)$ [8]. The North American ROC reported that, between 2006 and 2010, survival to discharge after OHCA increased from 8.2 to $10.4 \%$ [3]. The best outcomes occur in patients with a witnessed primary cardiac arrest and an initial shockable rhythm (ventricular fibrillation/pulseless ventricular tachycardia, VF/pVT). Recent London Ambulance Service data show survival to hospital discharge for these patients has increased from $5 \%$ in $2001 / 2002$, to $12 \%$ in $2007 / 2008$, and to $31.5 \%$ in 2015/2016 [9].

After return of spontaneous circulation (ROSC), most OHCA survivors are comatose or have another indication for tracheal intubation and mechanical ventilation $[10,11]$. Retrospective UK data from the Intensive Care National Audit and Research Centre between 2004 and 2014 showed that survivors of OHCA $(n=29,621)$ accounted for an increasing proportion of all mechanically ventilated admissions to ICUs (3.5\% in 2004, 5.8\% in 2014) [12]. Risk-adjusted hospital mortality following admission to ICU after in-hospital cardiac arrest (IHCA) and OHCA combined decreased significantly during this period (OR 0.96 per year). An Australian study of 3449 OHCA survivors between 2000 and 2014 reported a mean survival of 11.9 years, and a 1-, 10-, and 15-year survival of 92.2, 70.1 and $62.3 \%$, respectively [13]. After 5 years, the standardised mortality rate for survivors was similar to the general population.

The quality of survival after cardiac arrest is most commonly assessed using the Cerebral Performance Category (CPC) or Modified Rankin Scale (mRS), with a CPC of
1-2 or a mRS of $0-3$ considered a good neurological outcome. CARES data for 2015 showed that $81 \%$ of those surviving to hospital discharge had a CPC score of 1 or 2 [2]. Although most survivors have a good CPC or mRS outcome, these scales do not identify more subtle impairments in cognitive function or impairments in functional outcomes.

Importantly, $\mathrm{CPC}$ and mRS improve in survivors over time. In Denmark, 610 (76.6\%) of the 796 cardiac arrest survivors between 2001 and 2011, who had been employed before their cardiac arrest, returned to work in a median time of 4 months [14]. The proportion of survivors returning to work increased over time, from $66.1 \%$ in $2001-2005$ to $78.1 \%$ in $2006-2011(P=0.002)$. When 287 survivors of OHCA from a targeted temperature management (TTM) study were compared with 119 matched control patients with ST-segment-elevation myocardial infarction (STEMI) without OHCA at 180 days, attention/mental speed was more affected among cardiac arrest patients, but memory and executive functioning were similar [15]. The OHCA survivors also reported a more restricted societal participation and a lower return to work [16]. The Parisian registry compared health-related quality of life (HRQoL) data at a median of 50 months in 255 OHCA survivors with the general population using the Short Form 36 (SF-36) questionnaire [17]. In CPC 1 patients, HRQoL was similar to age- and gender-matched controls in the general population, whereas those with worse neurological outcomes (CPC 2 or 3) also had a worse HRQoL across most SF-36 dimensions.

\section{Disparities in organisation and outcome Variations in community response}

Although several studies show a marked variation in OHCA survival across countries and regions, factors underlying this outcome variation remain incompletely explained $[1,4,18,19]$. These geographical disparities in outcome may be associated with factors affecting each link in the chain of survival. A substantial proportion of the variation across countries seems to reflect differences in bystander response across communities (Table 1). Social economic and education disparities could explain some of this variation. In Australia, significant heterogeneity in rates of bystander-CPR and survival have been documented across rural and metropolitan regions [20]. Neighbourhood characteristics may influence rates of bystander-initiated CPR. A large US cohort study $(n=14,225)$ showed that patients who had an OHCA in low-income black neighbourhoods were less likely to receive bystander-initiated CPR than those in highincome white neighbourhoods [21]. This was confirmed in a recent study which documented that the lowest rates 
Table 1 Potential interventions by health authorities aimed at improving outcome from cardiac arrest

\begin{tabular}{lll}
\hline Identified issues & $\begin{array}{l}\text { Assistance that could be offered by health } \\
\text { authorities }\end{array}$ & Expected effect \\
\hline $\begin{array}{ll}\text { Management } \\
\text { Low rate of bystander CPR and AED use }\end{array}$ & $\begin{array}{l}\text { Public education } \\
\text { Spreading new technologies (smartphone apps, } \\
\text { drones) } \\
\text { Deploying more public access AEDs } \\
\text { Deploying drone-delivered AED programs in } \\
\text { remote areas }\end{array}$ & $\begin{array}{c}\text { Improvement in survival rate and neurological } \\
\text { recovery }\end{array}$ \\
\hline Difficulties in AED location & $\begin{array}{l}\text { Register AEDs with EMS } \\
\text { Mandatory GPS location in all devices }\end{array}$ & Rapid access to defibrillation \\
\hline Inadequate post-resuscitation management & $\begin{array}{l}\text { Implementation of cardiac arrest receiving centres } \\
\text { and networks }\end{array}$ & Enhancement of brain and cardiac management \\
\hline Inadequate rehabilitation & $\begin{array}{l}\text { Dedicated resources } \\
\text { Large national and international registries }\end{array}$ & Improvement in HRQL for survivors \\
\hline Geographical disparities in outcome & Improvement in EMS organisation \\
\hline
\end{tabular}

CPR cardiopulmonary resuscitation, $A E D$ automated external defibrillator, EMS emergency medical services, GPS global positioning satellite, $H R Q D L$ health-related quality of life

of bystander CPR and AED use occurred in predominantly black neighbourhoods, and that these neighbourhoods had a significantly lower likelihood for OHCA survival compared with predominantly white neighbourhoods [22]. Improving bystander interventions in these neighbourhoods may improve cardiac arrest survival. In a cross-sectional telephone survey, lesser education and lower income were associated with reduced likelihood of CPR training, illustrating the need to develop tailored CPR education to address this variability [23]. Language barriers for comprehension and implementation of telephone-CPR were also identified. In a recent US study that focused on Spanish-speaking callers, the average time for the dispatcher to recognize need for CPR was two times longer than with English-speaking callers, and this resulted in longer delays to first compression [24].

\section{Variations in emergency medical services systems}

There are marked differences in the organisation of EMS, but it is unclear if this contributes to disparities in OHCA outcome. Ambulance crews using advanced life support (ALS) are staffed and equipped to provide sophisticated care on site, whereas basic life support gives priority to rapid transport with only minimal treatment at the scene. The ALS crews can provide more sophisticated interventions, such as tracheal intubation for airway management and intravenous catheters for drug and fluid delivery, but they spend more time at the scene on average and their cost is higher. In a multicentre, controlled clinical trial conducted in 17 Canadian cities and enrolling 5638 OHCA patients, the implementation of ALS interventions did not improve the rate of survival [25]. More recently, several studies have questioned the usefulness of ALS interventions in OHCA, including airway management [26, 27], adrenaline (epinephrine) $[28,29]$, or anti-arrhythmic drugs [30]. In many parts of the world, ALS ambulances are also staffed with a physician specialist in emergency medicine. One study that used propensity analysis documented that the presence of a physician on the ambulance was associated with better short- and long-term outcome after OHCA [31], but other studies have failed to show benefit for prehospital physicians [32]. The findings of a recent systematic review were consistent with this benefit and suggested that physician-guided resuscitation may improve survival outcomes after OHCA [33], but the cost-effectiveness of this policy is controversial.

\section{Regionalisation of cardiac arrest care}

The wide disparities in outcome across institutions receiving OHCA patients led the American Heart Association (AHA) to recommend in 2010 the implementation of regional cardiac resuscitation centres for post-resuscitation care following OHCA [34]. This AHA policy stated that the essential elements of a 'Level 1' cardiac arrest centre should encompass an extensive experience with TTM, a 24-h/day capability for cardiac catheterisation laboratory, advanced haemodynamic support and treatment of re-arrest, the ability to perform electrophysiology testing and defibrillator assessment and placement, processes to ensure appropriate timing and methods of neurological prognostication, and finally a comprehensive multidisciplinary performance improvement program to continuously track outcomes [34]. In Arizona, implementation of a system of cardiac arrest centres (bypassing smaller hospitals) was independently associated with increased overall survival and favourable neurological outcome, particularly among 
patients with witnessed shockable rhythms [35]. Outside of the US, the concept of cardiac arrest centres, although being informally accepted, is not firmly established and implemented. In the UK, for example, only $13 \%$ of acute hospitals could meet these requirements [36].

Considering the uncertainty about disparities in outcome, there is an urgent need to establish national and international comparisons focusing in particular on public education, EMS organisation and cardiac arrest pathways. This may come from large registries that should be supported by health authorities.

\section{Recent advances and ongoing controversies in cardiopulmonary resuscitation \\ Recent advances in the community response}

Bystander CPR increases 30-day survival from OHCA by 2-3 times [37, 38]. Many EMS systems around the world have implemented telephone CPR systems whereby the dispatcher guides the bystander to provide chest compressions while awaiting arrival of EMS personnel. These telephone systems can significantly increase bystander CPR rates, survival to hospital discharge and survival with good neurological outcome [39-41]. Use of smartphones, which are generally equipped with global positioning system (GPS) technology, enables trained volunteers within 500-1000 $\mathrm{m}$ of a cardiac arrest to be dispatched by short message system messages (Fig. 1). In a randomised controlled trial involving $667 \mathrm{OHCAs}$, such a system increased the rate of bystander CPR from 48 to $62 \%(P<0.001)$ [42]. Since use of public access AEDs

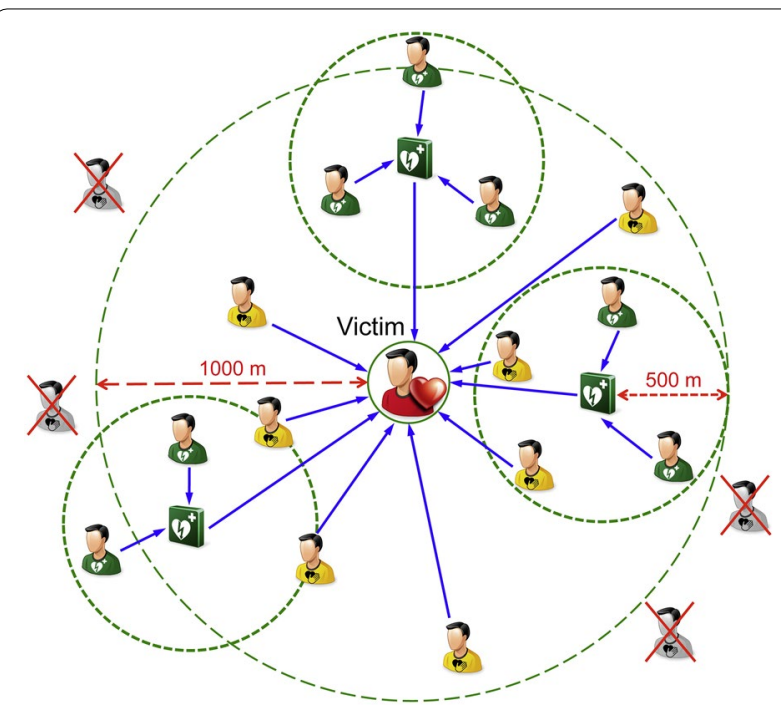

Fig. 1 A text message alert system in North Holland. When a dispatcher suspects an out-of-hospital cardiac arrest, trained first responders within $1000 \mathrm{~m}$ are alerted to either first retrieve an automated external defibrillator (if within $500 \mathrm{~m}$ ) and then go to the victim or to go directly to the victim and start CPR [44]. Reproduced with permission from Resuscitation improve outcome [43], such GPS systems can also be used to guide volunteer responders to retrieve a nearby AED. This enables even faster defibrillation [44], but is dependent on the location of public access AEDs being registered with the local EMS. Unfortunately, the location of such AEDs is often unknown to the EMS, and this must be updated in the future. Finally, the use of drones to deliver AEDs to the scene of a cardiac arrest has been evaluated and shown to be feasible [45].

The impact on outcome of ALS interventions remains unclear for both OHCA and IHCA. The optimal airway management technique is likely to vary during the resuscitation attempt and will depend on the skills of the rescuers and practice/logistics within each system. A randomised clinical trial of tracheal intubation versus bag-mask ventilation in OHCA (with intubation delayed until after ROSC) undertaken by prehospital physicians in France and Belgium showed no difference in favourable neurological outcome at 28 days [26]. Two recently completed but unpublished cluster randomised trials of a supraglottic airway (SGA) versus tracheal intubation will provide further data on airway management in OHCA [46, 47].

In a randomised trial in 851 OHCA patients, use of intravenous drugs following the existing guidelines compared with no use of drugs had no significant effect on long-term outcome [48]. The impact of adrenaline on long-term outcome after cardiac arrest has never been evaluated in an appropriately powered randomised controlled trial. A single under-powered randomised controlled trial and 14 observational studies which compared adrenaline (1 mg every 3-5 min) with no adrenaline indicate that the rate of ROSC is doubled [ $(19.7$ vs. $5.5 \%$; OR 2.85 (95\% CI 2.28-3.54)] but fewer patients survived with favourable neurological outcomes [1.9 vs. 2.2\%; OR 0.51 (95\% CI 0.31-0.84)] [49, 50]. An RCT comparing adrenaline with placebo in OHCA has just completed enrolment of over 8000 patients, but has yet to be published [51].

Mechanical CPR devices enable high-quality CPR to be provided for prolonged periods and during transport. However, meta-analysis of five RCTs comparing mechanical CPR with manual CPR found no significant improvement in initial survival, survival to discharge/30 days [OR 0.89 (95\% CI 0.77-1.02)] or favourable neurological outcome [OR $0.76(95 \%$ CI 0.53, 1.11)] [52]. Despite these neutral studies, the use of mechanical CPR devices is still recommended for prolonged CPR, during transport to more advanced in-hospital treatment (e.g. extracorporeal-CPR, E-CPR) or during interventions in the cardiac catheterisation laboratory [53].

Extracorporeal CPR in the form of veno-arterial extracorporeal membrane oxygenation is being implemented in many healthcare systems. A systematic review and meta-analysis of observational data documented an 
association between use of E-CPR and an increase in survival and favourable neurological outcome [54]. There are significant challenges posed in implementing E-CPR, not least cost and local expertise in the technique. Outcomes are likely to be optimised by adhering strictly to evidence-based inclusion and exclusion criteria $[55,56]$.

\section{Post-resuscitation care: current practice and ongoing controversies \\ Coronary angiography}

In patients resuscitated from OHCA without an obvious non-cardiac cause, the prevalence of an acute coronary artery lesion ranges from 59 to 71\% [57]. Observational evidence shows that, in resuscitated OHCA of suspected cardiac origin with ST segment elevation (STE) or left bundle branch block on post-ROSC electrocardiogram (ECG), emergent coronary angiography and PCI when appropriate are associated with increased survival and favourable neurological outcome, and are currently recommended [57]. In patients without STE on the postROSC ECG, the potential benefits of early invasive management are currently under investigation in several randomised trials (NCT02309151, NCT02387398, NCT02750462). In patients with refractory OHCA from $\mathrm{VF} / \mathrm{pVT}$, and admitted to hospital with ongoing CPR, an early invasive management bundled with E-CPR resulted in a $42 \%$ rate of survival to discharge with good neurological outcome [58].

\section{Targeted temperature management}

Fever is common after CA and is mainly related to an inflammatory response during the reperfusion phase. TTM at $33-36{ }^{\circ} \mathrm{C}$ is a key element of post-resuscitation care and can be achieved using both invasive and noninvasive techniques [59]. There is inconclusive evidence whether any temperature target is better than another, and there is variation in practice throughout Europe [60] as well as North America. If the target is $36{ }^{\circ} \mathrm{C}$, efforts should be made to stay within target and avoiding higher temperatures [61]. The recommended duration of TTM should be at least $24 \mathrm{~h}$ [62]. In unconscious survivors of OHCA, TTM at $33{ }^{\circ} \mathrm{C}$ for $48 \mathrm{~h}$ did not significantly improve 6-month neurological outcome compared with TTM for $24 \mathrm{~h}$ [62]; however, survival was very high in both groups. A phase 3 TTM-2 trial has just started recruiting and is comparing comatose post-OHCA patients treated with TTM at $33{ }^{\circ} \mathrm{C}$ versus standard care avoiding fever $\left(\leq 37.8^{\circ} \mathrm{C}\right)(\mathrm{NCT} 02908308)$. Cardiac arrest patients are complex and heterogeneous, and it is likely that the optimal treatment strategy will depend on the cause of cardiac arrest, the severity of the reperfusion injury and the haemodynamic status of each patient. The evidence for the use of TTM after IHCA is inconclusive, and intensivists should use clinical judgement when applying TTM for IHCA patients [63].

\section{Oxygenation targets}

Observational evidence suggests that extreme hyperoxia $\left(\mathrm{PaO}_{2}>300 \mathrm{mmHg}\right.$ or $\left.40 \mathrm{kPa}\right)$ after CA may be harmful [64]. In an RCT involving patients with prehospital STEMI, but not cardiac arrest, routine oxygen therapy, compared with oxygen only if $\mathrm{SpO}_{2}<94 \%$, resulted in significantly larger infarct size [65]. In another recent RCT of more than 6000 patients with suspected acute myocardial infarction, oxygen $6 \mathrm{lpm}$ for 6-12 h compared with air did not reduce death at 365 days, the primary endpoint [66]. A phase 3 study (EXACT), involving titration of oxygen to a target $\mathrm{SpO}_{2}$ 90-94\% as soon as possible after ROSC in OHCA, has just started recruiting (NCT02499042). Pending the results of this trial, the inspired fraction of oxygen after ROSC should be titrated to maintain the arterial blood oxygen saturation in the range of 94-98\% [57].

\section{Post-resuscitation ventilation}

Hypercapnia is common immediately after ROSC, while iatrogenic hypocapnia due to hyperventilation may occur especially during TTM and worsen cerebral ischaemia [67]. Hypercapnia might increase blood flow to ischaemic brain, and observational studies have documented an association between mild hypercapnia and better neurological outcome $[68,69]$ and better cerebral oxygenation [70] among post-cardiac arrest patients. A phase 2 study comparing mild hypercapnia with normocapnia in 50 post-arrest patients documented a lesser increase in neuron-specific enolase (NSE) values in the hypercapnia group [71]. A phase 3 study (TAME) of normocapnia versus mild hypercapnia [6.6-7.3 $\mathrm{kPa}(50-55 \mathrm{mmHg})]$ in post-cardiac arrest patients will soon start recruiting (NCT03114033). Current recommendations are that ventilation should be titrated to target normocapnia [57]. A protective lung ventilation (tidal volume $6-8 \mathrm{ml} \mathrm{kg}$ ideal body weight and positive end expiratory pressure 4-8 $\mathrm{cm} \mathrm{H}_{2} \mathrm{O}$ ) is recommended and may be beneficial in OHCA patients [72].

\section{Blood pressure targets}

Intensivists will often control the blood pressure with vasoactive medicines, but the optimal target is not clear. Each individual probably has different minimum pressures for adequate perfusion of various organs based on their history of hypertension and current vascular tone. Cerebral autoregulation is disturbed in a third of comatose post-cardiac arrest patients [73], and optimal perfusion of the injured brain may require higher mean arterial pressures (perhaps $85-100 \mathrm{mmHg}$ ) than typically selected in non-brain-injured patients $(>65 \mathrm{mmHg}$ ) [74]. 


\section{Prognostication}

Two-thirds of deaths occurring in patients who are admitted comatose to ICU after ROSC follow withdrawal of life-sustaining treatment (WLST) because of presumed irreversible hypoxic-ischaemic brain injury (HIBI) [75]. Ensuring optimal prognostication is essential to avoid potential harm resulting from an inappropriate WLST. Before prognostic assessment is made, major confounders-such as residual sedation or neuromuscular blockade-should be excluded and, for this reason, using short-acting drugs is preferable [76]. In patients who are unconscious with absent or extensor motor response to pain at $72 \mathrm{~h}$ or more after ROSC, a bilateral absence of N20 wave of somatosensory-evoked potentials and/or bilateral absent pupillary response to light predicts severe neurological disability or death with $<5 \%$ false positive rate and narrow confidence intervals [57]. When these signs are absent, a combination of two or more among early status myoclonus, high blood values of NSE, or signs of severe HIBI on brain-computed tomography or EEG also suggests a poor neurological outcome, but the confidence in this prediction will be lower. If none of these conditions is present, the prognosis is indeterminate and further observation is indicated. This can be prolonged, since delayed awakening is common in patients with an eventually good outcome after cardiac arrest [77].

Acquired brain injury patients who have early (first week) mobilisation and rehabilitative interventions show more improvement in functional measures than patients without early mobilisation [78].

\section{Future directions}

Priority areas for future research in cardiac arrest have recently been defined [79, 80]. Adequately-powered randomised trials are the gold standard for evidence of the efficacy and effectiveness as well as implementation of interventions in patients with acute cardiovascular conditions. Randomised controlled trials for efficacy are relatively rare in resuscitation science. Even so, when a treatment, an intervention or a system of care changes is based on the highest level of evidence, while adoption and widespread implementation take time. Several factors reduce the rate of evidence-based change in clinical practice related to treatment of patients with OHCA. Some of these factors may be modifiable by clinicians, researchers and policy makers.

The first modifiable factor is the lack of resources dedicated to support high-quality randomised trials in resuscitation (Table 2). Resources for healthcare research are limited. Cardiac arrest research is underfunded compared to other clinical disorders [81]. The Resuscitation Outcomes Consortium (ROC) was a North American multi-centre clinical research network designed to conduct clinical out-of-hospital trials of therapies for cardiac arrest and major trauma. Over a 10-year period, communities that participated in ROC observed a doubling of survival after $\mathrm{OHCA}[3,82]$. This suggests that outcomes after $\mathrm{OHCA}$ can be improved, and that further investments in research and implementation warrant consideration. Multinational collaborations will facilitate the rate of recruitment into randomised trials and is a strategy increasingly being adopted in resuscitation research.

The second modifiable factor that would facilitate the implementation of randomised trials in resuscitation is global uniformity in the approach to enabling trials to use waivers of informed consent. Patients in cardiac arrest cannot provide individual consent before they are enrolled in a clinical trial. There is considerable variation in policies and procedures related to exemption from informed consent for emergency research [83, 84]. In some settings, waiver of consent is not permitted, and the investigator must seek deferred consent or consent may be required for ongoing participation in a clinical trial. Either approach may introduce bias if those who consent have different baseline characteristics or outcome as compared to those who do not [85].

A third modifiable factor is the analytical approach for cardiac arrest trials. Overall, survival after OHCA with any initial rhythm is low. Traditionally, randomised resuscitation trials use fixed sample size to compare the effect of one or more interventions compared to standard care. Ordinarily, such trials use logistic regression to evaluate survival to discharge or good neurologic status at discharge. Fixed or group sequential methods may require many subjects to detect a clinically important difference in such binary outcomes because of the low overall rate of success after resuscitation. As a consequence, some

Table 2 Potential interventions by health authorities aimed at facilitating cardiac arrest research

\begin{tabular}{ll}
\hline Identified issues & Assistance that could be offered by health authorities \\
Underfunded clinical research & Appropriate academic funding \\
Difficulties in obtaining consent for research & Global uniformity in the approach to waiver of informed consent \\
Complexity in follow-up & Authorising follow-up data obtained by linkage to administrative data sources \\
Inappropriate endpoints in clinical research & Encouraging the use of patient-reported outcomes
\end{tabular}


recent randomised trials have sought to enroll several thousand subjects or more over several years to detect the minimum clinically important difference in survival $[51,86]$. There is a need to accelerate the processes and efficiency of future trials. Adaptive trial designs which use accumulating data to inform changes to the study as it progresses may accelerate generation of knowledge and reduce cost [87]. However, this may be at the expense of the reliability of the treatment estimates derived from the trial [88]. Bayesian approaches which make use of prior information can be used to provide a quantitative summary of treatment effect when traditional approaches for defining statistical significance are impractical [89]. Registry-based trials and trials which obtain follow-up data through administrative data sources may reduce the burden and cost of data collection [90,91]. These are very challenging to do well and meet the privacy and ethical concerns which appear to evolve, often across legislations [92].

The fourth modifiable approach to randomised cardiac arrest trials is the definition of the primary outcome of interest. Traditionally, most trials have measured survival to hospital discharge, as this measure is convenient, least costly and unbiased. Neurological favourable outcome at discharge or 30 days is also a useful measure and is collected in many OHCA trials. The use of hospital-free survival, assessed as the number of days alive and out of hospital during the first 30 days post-arrest may provide statistical efficiency over dichotomous outcomes such as survival and favourable neurological outcome [93]. Although this is measurable and may reduce sample size requirements in costly randomised trials, like progression-free survival in cancer, there is controversy about the usefulness of this measure in cardiac arrest trials [94, 95].

Outcomes preferred by investigators may not be what is important to patients. Trials involving critically ill patients rarely measure patient-reported outcomes as the primary or secondary outcome measure (5 vs. $22 \%$, respectively) [96]. Patients and their family members involved in the Core Outcomes Set for Cardiac Arrest (COSCA) process identified survival, neurological function and HRQoL as the preferred outcome measures [97]. To date, studies of post-discharge outcomes have provided conflicting evidence of the magnitude of impairment after cardiac arrest [15, 86, 98, 99]. These discordant results may partly reflect differences in the timing and method of measurement. Proximate assessments are easier to obtain but may not fully reflect patient recovery; downstream assessments may more fully reflect recovery but are harder to obtain, add significantly to the cost of the trial and delay study completion.
The final modifiable factor is the need to have a translation or implementation component to each randomised trial. Many granting agencies include a knowledge translation requirement for all grants hoping to move the responsibility for scientific advancements from bench to bedside into the hands of the investigator. This intervention alone has not had an impact and there are large delays in implementation. The emphasis appears to be shifting to those responsible for publishing guidelines and making policy [100]. The International Liaison Committee on Resuscitation (ILCOR) is moving to a continuous evidence review process where systematic reviews of high priority research questions are posted and council guidelines will change accordingly (http://www.ilcor.org) [101]. This may not be enough for policy to change. Scaling-up and spread of effective health interventions may require a more novel approach of partnerships [102]. We anticipate that partnerships between ILCOR, the World Health Organization and the Global Resuscitation Alliance, for example, might generate the impetus for change.

\section{Author details}

${ }^{1}$ Bristol Medical School, University of Bristol, Bristol, UK. ${ }^{2}$ Anaesthesia and Intensive Care Medicine, Royal United Hospital, Bath, UK. ${ }^{3}$ Pediatric Critical Care Medicine, Russell Raphaely Endowed Chair of Critical Care Medicine, The Children's Hospital of Philadelphia, Philadelphia, USA. ${ }^{4}$ Anesthesiology and Critical Care Medicine, The University of Pennsylvania Perelman School of Medicine, Philadelphia, USA. ${ }^{5}$ Department of Emergency Medicine, University of Pittsburgh School of Medicine, Pittsburgh, PA, USA. ${ }^{6}$ Rescu, St.Michael's Hospital, 30 Bond St, Toronto, ON M5B 1W8, Canada. ${ }^{7}$ Department of Anesthesia and Critical Care Medicine, The Children's Hospital of Philadelphia, 3401 Civic Center Blvd, Philadelphia, PA 19104, USA. ${ }^{8}$ Warwick Medical School and Heart of England NHS Foundation Trust, University of Warwick, Coventry CV4 7AL, UK. ${ }^{9}$ Istituto Anestesiologia E Rianimazione, Università Cattolica del Sacro Cuore, Fondazione Policlinico Universitario "Agostino Gemelli", Largo Francesco Vito, 1, 00168 Rome, Italy. ${ }^{10}$ Division of Intensive Care, Department of Anaesthesiology, Intensive Care and Pain Medicine, Helsinki University Hospital and University of Helsinki, Haartmaninkatu 4, 00029 HUS Helsinki, Finland. ${ }^{11}$ Intensive Care Medicine, Southmead Hospital, North Bristol NHS Trust, Bristol BS10 5NB, UK. ${ }^{12}$ Department of Anaesthesiology, Division of Emergencies and Critical Care, Oslo University Hospital and Institute of Clinical Medicine, University of Oslo, Oslo, Norway. ${ }^{13}$ Medical ICU, Cochin Hospital (AP-HP), Paris-Cardiovascular-Research-Centre, INSERM U970 (Sudden Death Expertize Centre), Paris, France. ${ }^{14}$ Université Paris-Descartes-SorbonneParis-Cité, Paris, France.

\section{Compliance with ethical standards}

\section{Conflicts of interest}

JPN: Editor-in-Chief, Resuscitation; funding from the National Institute for Health Research to evaluate interventions in cardiac arrest including airway management (AIRWAYS-2 Study) and adrenaline (PARAMEDIC-2 Study). RAB: None declared. CC: None declared. LJM: None declared. VN: None declared. GDP: Funding from the National Institute for Health Research to evaluate interventions in cardiac arrest including mechanical CPR and adrenaline (PARAMEDIC-2 Study). CS: None declared. MS: Research grant from GE Healthcare, travel reimbursements and lecture fees from COVIDIEN, Astellas Pharma, Axis-Shield and BARD. JS: Editor, Resuscitation. KS: None declared. AC: Speakers fees and travel grants from Bard Medical. 
Received: 31 March 2018 Accepted: 12 May 2018

Published online: 2 June 2018

\section{References}

1. Grasner JT, Lefering R, Koster RW et al (2016) EuReCa ONE-27 Nations, ONE Europe, ONE Registry: a prospective one month analysis of out-ofhospital cardiac arrest outcomes in 27 countries in Europe. Resuscitation 105:188-195

2. Benjamin EJ, Blaha MJ, Chiuve SE et al (2017) Heart disease and stroke statistics-2017 update: a report from the American Heart Association. Circulation 135:e146-e603

3. Daya MR, Schmicker RH, Zive DM et al (2015) Out-of-hospital cardiac arrest survival improving over time: results from the Resuscitation Outcomes Consortium (ROC). Resuscitation 91:108-115

4. Girotra S, van Diepen S, Nallamothu BK et al (2016) Regional variation in out-of-hospital cardiac arrest survival in the United States. Circulation 133:2159-2168

5. Becker LB, Aufderheide TP, Graham R (2015) Strategies to improve survival from cardiac arrest: a report from the Institute of Medicine. JAMA 314:223-224

6. Nolan JP, Perkins GD, Soar J (2015) Improving survival after out-ofhospital cardiac arrest. BMJ 351:h4989

7. Wissenberg M, Lippert FK, Folke F et al (2013) Association of national initiatives to improve cardiac arrest management with rates of bystander intervention and patient survival after out-of-hospital cardiac arrest. JAMA 310:1377-1384

8. Kragholm K, Wissenberg M, Mortensen RN et al (2017) Bystander efforts and 1-year outcomes in out-of-hospital cardiac arrest. N Engl J Med 376:1737-1747

9. Virdi G, Picton S, Fothergill R, Whitbread M (2016) Cardiac arrest annual report: 2015/16. London Ambulance Service, London

10. Berg KM, Grossestreuer AV, Uber A, Patel PV, Donnino MW (2017) Intubation is not a marker for coma after in-hospital cardiac arrest: a retrospective study. Resuscitation 119:18-20

11. Deakin CD, Fothergill R, Moore F, Watson L, Whitbread M (2014) Level of consciousness on admission to a Heart Attack Centre is a predictor of survival from out-of-hospital cardiac arrest. Resuscitation 85:905-909

12. Nolan JP, Ferrando P, Soar J et al (2016) Increasing survival after admission to UK critical care units following cardiopulmonary resuscitation. Crit Care 20:219

13. Andrew E, Nehme Z, Wolfe R, Bernard S, Smith K (2017) Long-term survival following out-of-hospital cardiac arrest. Heart 103:1104-1110

14. Kragholm K, Wissenberg M, Mortensen RN et al (2015) Return to work in out-of-hospital cardiac arrest survivors: a nationwide register-based follow-up study. Circulation 131:1682-1690

15. Lilja G, Nielsen N, Friberg H et al (2015) Cognitive function in survivors of out-of-hospital cardiac arrest after target temperature management at $33^{\circ} \mathrm{C}$ versus $36^{\circ} \mathrm{C}$. Circulation 131:1340-1349

16. Lilja G, Nielsen N, Bro-Jeppesen J et al (2018) Return to work and participation in society after out-of-hospital cardiac arrest. Circ Cardiovasc Qual Outcomes 11:e003566

17. Geri G, Dumas F, Bonnetain F et al (2017) Predictors of long-term functional outcome and health-related quality of life after out-of-hospital cardiac arrest. Resuscitation 113:77-82

18. Nichol G, Thomas E, Callaway CW et al (2008) Regional variation in outof-hospital cardiac arrest incidence and outcome. JAMA 300:1423-1431

19. Okubo M, Kiyohara K, Iwami T, Callaway CW, Kitamura T (2017) Nationwide and regional trends in survival from out-of-hospital cardiac arrest in Japan: a 10-year cohort study from 2005 to 2014. Resuscitation 115:120-128

20. Nehme Z, Bernard S, Cameron P et al (2015) Using a cardiac arrest registry to measure the quality of emergency medical service care: decade of findings from the Victorian Ambulance Cardiac Arrest Registry. Circ Cardiovasc Qual Outcomes 8:56-66

21. Sasson C, Magid DJ, Chan P et al (2012) Association of neighborhood characteristics with bystander-initiated CPR. N Engl J Med 367:1607-1615
22. Starks MA, Schmicker RH, Peterson ED et al (2017) Association of neighborhood demographics with out-of-hospital cardiac arrest treatment and outcomes: where you live may matter. JAMA Cardiol 2:1110-1118

23. Blewer AL, Ibrahim SA, Leary $M$ et al (2017) Cardiopulmonary resuscitation training disparities in the united states. J Am Heart Assoc 6:e006124

24. Nuno T, Bobrow BJ, Rogge-Miller KA et al (2017) Disparities in telephone CPR access and timing during out-of-hospital cardiac arrest. Resuscitation 115:11-16

25. Stiell IG, Wells GA, Field B et al (2004) Advanced cardiac life support in out-of-hospital cardiac arrest. N Engl J Med 351:647-656

26. Jabre P, Penaloza A, Pinero D et al (2018) Effect of Bag-mask ventilation vs endotracheal intubation during cardiopulmonary resuscitation on neurological outcome after out-of-hospital cardiorespiratory arrest: a randomized clinical trial. JAMA 319:779-787

27. Hasegawa K, Hiraide A, Chang Y, Brown DF (2013) Association of prehospital advanced airway management with neurologic outcome and survival in patients with out-of-hospital cardiac arrest. JAMA 309:257-266

28. Hagihara A, Hasegawa M, Abe T, Nagata T, Wakata Y, Miyazaki S (2012) Prehospital epinephrine use and survival among patients with out-ofhospital cardiac arrest. JAMA 307:1161-1168

29. Dumas F, Bougouin W, Geri G et al (2014) Is epinephrine during cardiac arrest associated with worse outcomes in resuscitated patients? J Am Coll Cardiol 64:2360-2367

30. Kudenchuk PJ, Brown SP, Daya M et al (2016) Amiodarone, lidocaine, or placebo in out-of-hospital cardiac arrest. N Engl J Med 374:1711-1722

31. Hagihara A, Hasegawa M, Abe T, Nagata T, Nabeshima Y (2014) Physician presence in an ambulance car is associated with increased survival in out-of-hospital cardiac arrest: a prospective cohort analysis. PLoS ONE 9:e84424

32. Olasveengen TM, Lund-Kordahl I, Steen PA, Sunde K (2009) Out-of hospital advanced life support with or without a physician: effects on quality of CPR and outcome. Resuscitation 80:1248-1252

33. Bottiger BW, Bernhard M, Knapp J, Nagele P (2016) Influence of EMSphysician presence on survival after out-of-hospital cardiopulmonary resuscitation: systematic review and meta-analysis. Crit Care 20:4

34. Nichol G, Aufderheide TP, Eigel B et al (2010) Regional systems of care for out-of-hospital cardiac arrest: a policy statement from the American Heart Association. Circulation 121:709-729

35. Spaite DW, Bobrow BJ, Stolz U et al (2014) Statewide regionalization of postarrest care for out-of-hospital cardiac arrest: association with survival and neurologic outcome. Ann Emerg Med 64(496-506):e1

36. Ford AH, Clark T, Reynolds EC et al (2016) Management of cardiac arrest survivors in UK intensive care units: a survey of practice. J Intensive Care Soc 17:117-121

37. Hasselqvist-Ax I, Riva G, Herlitz J et al (2015) Early cardiopulmonary resuscitation in out-of-hospital cardiac arrest. N Engl J Med 372:2307-2315

38. Rajan S, Wissenberg M, Folke F et al (2016) Association of bystander cardiopulmonary resuscitation and survival according to ambulance response times after out-of-hospital cardiac arrest. Circulation 134:2095-2104

39. Bobrow BJ, Spaite DW, Vadeboncoeur TF et al (2016) Implementation of a regional telephone cardiopulmonary resuscitation program and outcomes after out-of-hospital cardiac arrest. JAMA Cardiol 1:294-302

40. Ro YS, Shin SD, Lee YJ et al (2017) Effect of dispatcher-assisted cardiopulmonary resuscitation program and location of out-of-hospital cardiac arrest on survival and neurologic outcome. Ann Emerg Med 69(52-61):e1

41. Wu Z, Panczyk M, Spaite DW et al (2018) Telephone cardiopulmonary resuscitation is independently associated with improved survival and improved functional outcome after out-of-hospital cardiac arrest. Resuscitation 122:135-140

42. Ringh M, Rosenqvist M, Hollenberg J et al (2015) Mobile-phone dispatch of laypersons for CPR in out-of-hospital cardiac arrest. N Engl J Med 372:2316-2325

43. Holmberg MJ, Vognsen M, Andersen MS, Donnino MW, Andersen LW (2017) Bystander automated external defibrillator use and clinical outcomes after out-of-hospital cardiac arrest: a systematic review and meta-analysis. Resuscitation 120:77-87 
44. Zijlstra JA, Stieglis R, Riedijk F, Smeekes M, van der Worp WE, Koster RW (2014) Local lay rescuers with AEDs, alerted by text messages, contribute to early defibrillation in a Dutch out-of-hospital cardiac arrest dispatch system. Resuscitation 85:1444-1449

45. Claesson A, Backman A, Ringh M et al (2017) Time to delivery of an automated external defibrillator using a drone for simulated out-of-hospital cardiac arrests vs emergency medical services. JAMA 317:2332-2334

46. Wang HE, Prince DK, Stephens SW et al (2016) Design and implementation of the Resuscitation Outcomes Consortium Pragmatic Airway Resuscitation Trial (PART). Resuscitation 101:57-64

47. Taylor J, Black S, Brett SJ et al (2016) Design and implementation of the AIRWAYS-2 trial: a multi-centre cluster randomised controlled trial of the clinical and cost effectiveness of the i-gel supraglottic airway device versus tracheal intubation in the initial airway management of out of hospital cardiac arrest. Resuscitation 109:25-32

48. Olasveengen TM, Sunde K, Brunborg C, Thowsen J, Steen PA, Wik L (2009) Intravenous drug administration during out-of-hospital cardiac arrest: a randomized trial. JAMA 302:2222-2229

49. Jacobs IG, Finn JC, Jelinek GA, Oxer HF, Thompson PL (2011) Effect of adrenaline on survival in out-of-hospital cardiac arrest: a randomised double-blind placebo-controlled trial. Resuscitation 82:1138-1143

50. Loomba RS, Nijhawan K, Aggarwal S, Arora RR (2015) Increased return of spontaneous circulation at the expense of neurologic outcomes: is prehospital epinephrine for out-of-hospital cardiac arrest really worth it? J Crit Care 30:1376-1381

51. Perkins GD, Quinn T, Deakin CD et al (2016) Pre-hospital assessment of the role of adrenaline: measuring the effectiveness of drug administration in cardiac arrest (PARAMEDIC-2): trial protocol. Resuscitation 108:75-81

52. Gates S, Quinn T, Deakin CD, Blair L, Couper K, Perkins GD (2015) Mechanical chest compression for out of hospital cardiac arrest: systematic review and meta-analysis. Resuscitation 94:91-97

53. Soar J, Nolan JP, Bottiger BW et al (2015) European resuscitation council guidelines for resuscitation 2015: section 3. Adult advanced life support. Resuscitation 95:100-147

54. Ouweneel DM, Schotborgh JV, Limpens J et al (2016) Extracorporeal life support during cardiac arrest and cardiogenic shock: a systematic review and meta-analysis. Intensive Care Med 42:1922-1934

55. Nolan JP, Sandroni C (2017) In this patient in refractory cardiac arrest should I continue CPR for longer than $30 \mathrm{~min}$ and if so, how? Intensive Care Med 43:1501-1503

56. Abrams D, Garan AR, Abdelbary A et al (2018) Position paper for the organization of ECMO programs for cardiac failure in adults. Intensive Care Med. https://doi.org/10.1007/s00134-018-5064-5

57. Nolan JP, Soar J, Cariou A et al (2015) European Resuscitation Council and European Society of Intensive Care Medicine 2015 guidelines for post-resuscitation care. Intensive Care Med 41:2039-2056

58. Yannopoulos D, Bartos JA, Raveendran G et al (2017) Coronary artery disease in patients with out-of-hospital refractory ventricular fibrillation cardiac arrest. J Am Coll Cardiol 70:1109-1117

59. Deye N, Cariou A, Girardie P et al (2015) Endovascular versus external targeted temperature management for patients with out-of-hospital cardiac arrest: a randomized, controlled study. Circulation 132:182-193

60. Storm C, Nee J, Sunde K et al (2017) A survey on general and temperature management of post cardiac arrest patients in large teaching and university hospitals in 14 European countries-the SPAME trial results. Resuscitation 116:84-90

61. Bray JE, Stub D, Bloom JE et al (2017) Changing target temperature from $33^{\circ} \mathrm{C}$ to $36^{\circ} \mathrm{C}$ in the ICU management of out-of-hospital cardiac arrest: a before and after study. Resuscitation 113:39-43

62. Kirkegaard H, Soreide E, de Haas I et al (2017) Targeted temperature management for 48 vs 24 hours and neurologic outcome after out-ofhospital cardiac arrest: a randomized clinical trial. JAMA 318:341-350

63. Chan PS, Berg RA, Tang Y, Curtis LH, Spertus JA, American Heart Association's Get With the Guidelines-Resuscitation I (2016) Association between therapeutic hypothermia and survival after in-hospital cardiac arrest. JAMA 316:1375-1382

64. Roberts BW, Kilgannon JH, Hunter BR et al (2018) Association between early hyperoxia exposure after resuscitation from cardiac arrest and neurological disability: a prospective multi-center protocol-directed cohort study. Circulation 137:2114-2124

65. Stub D, Smith K, Bernard S et al (2015) Air versus oxygen in ST-segmentelevation myocardial infarction. Circulation 131:2143-2150

66. Hofmann R, James SK, Jernberg T et al (2017) Oxygen therapy in suspected acute myocardial infarction. N Engl J Med 377:1240-1249

67. Pynnonen L, Falkenbach P, Kamarainen A, Lonnrot K, Yli-Hankala A, Tenhunen J (2011) Therapeutic hypothermia after cardiac arrest-cerebral perfusion and metabolism during upper and lower threshold normocapnia. Resuscitation 82:1174-1179

68. Schneider AG, Eastwood GM, Bellomo R et al (2013) Arterial carbon dioxide tension and outcome in patients admitted to the intensive care unit after cardiac arrest. Resuscitation 84:927-934

69. Vaahersalo J, Bendel S, Reinikainen M et al (2014) Arterial blood gas tensions after resuscitation from out-of-hospital cardiac arrest: associations with long-term neurologic outcome. Crit Care Med 42:1463-1470

70. Eastwood GM, Tanaka A, Bellomo R (2016) Cerebral oxygenation in mechanically ventilated early cardiac arrest survivors: the impact of hypercapnia. Resuscitation 102:11-16

71. Eastwood GM, Schneider AG, Suzuki S et al (2016) Targeted therapeutic mild hypercapnia after cardiac arrest: a phase II multi-centre randomised controlled trial (the CCC trial). Resuscitation 104:83-90

72. Beitler JR, Ghafouri TB, Jinadasa SP et al (2017) Favorable neurocognitive outcome with low tidal volume ventilation after cardiac arrest. Am J Respir Crit Care Med 195:1198-1206

73. Ameloot K, Genbrugge C, Meex I et al (2015) An observational nearinfrared spectroscopy study on cerebral autoregulation in post-cardiac arrest patients: time to drop 'one-size-fits-all' hemodynamic targets? Resuscitation 90:121-126

74. Ameloot K, Meex I, Genbrugge C et al (2015) Hemodynamic targets during therapeutic hypothermia after cardiac arrest: a prospective observational study. Resuscitation 91:56-62

75. Lemiale V, Dumas F, Mongardon N et al (2013) Intensive care unit mortality after cardiac arrest: the relative contribution of shock and brain injury in a large cohort. Intensive Care Med 39:1972-1980

76. Paul M, Bougouin W, Dumas F et al (2018) Comparison of two sedation regimens during targeted temperature management after cardiac arrest. Resuscitation. https://doi.org/10.1016/j.resuscitation.2018.03.025

77. Paul M, Bougouin W, Geri G et al (2016) Delayed awakening after cardiac arrest: prevalence and risk factors in the Parisian registry. Intensive Care Med 42:1128-1136

78. Bartolo M, Bargellesi S, Castioni CA et al (2017) Mobilization in early rehabilitation in intensive care unit patients with severe acquired brain injury: an observational study. J Rehabil Med 49:715-722

79. Nolan JP, Berg RA, Bernard S et al (2017) Intensive care medicine research agenda on cardiac arrest. Intensive Care Med 43:1282-1293

80. Kleinman ME, Perkins GD, Bhanji F et al (2018) ILCOR scientific knowledge gaps and clinical research priorities for cardiopulmonary resuscitation and emergency cardiovascular care: a consensus statement. Resuscitation 127:132-146

81. Coute RA, Panchal AR, Mader TJ, Neumar RW (2017) National institutes of health-funded cardiac arrest research: a 10-year trend analysis. J Am Heart Assoc 6:e005239

82. Buick JE, Drennan IR, Scales DC et al (2018) Improving temporal trends in survival and neurological outcomes after out-of-hospital cardiac arrest. Circ Cardiovasc Qual Outcomes 11:e003561

83. van Belle G, Mentzelopoulos SD, Aufderheide T, May S, Nichol G (2015) International variation in policies and practices related to informed consent in acute cardiovascular research: results from a 44 country survey. Resuscitation 91:76-83

84. Mentzelopoulos SD, Bossaert L, Raffay V et al (2016) A survey of key opinion leaders on ethical resuscitation practices in 31 European countries. Resuscitation 100:11-17

85. Nichol G, Powell J, van Ottingham L et al (2006) Consent in resuscitation trials: benefit or harm for patients and society? Resuscitation 70:360-368

86. Nichol G, Leroux B, Wang $\mathrm{H}$ et al (2015) Trial of continuous or interrupted chest compressions during CPR. N Engl J Med 373:2203-2214

87. Flight L, Julious SA, Goodacre S (2017) Can emergency medicine research benefit from adaptive design clinical trials? Emerg Med J 34:243-248 
88. Emerson SS, Fleming TR (2010) Adaptive methods: telling "the rest of the story". J Biopharm Stat 20:1150-1165

89. Laptook AR, Shankaran S, Tyson JE et al (2017) Effect of therapeutic hypothermia initiated after 6 hours of age on death or disability among newborns with hypoxic-ischemic encephalopathy: a randomized clinical trial. JAMA 318:1550-1560

90. Frobert O, Lagerqvist B, Olivecrona GK et al (2013) Thrombus aspiration during ST-segment elevation myocardial infarction. N Engl J Med 369:1587-1597

91. James S, Rao SV, Granger CB (2015) Registry-based randomized clinical trials_- new clinical trial paradigm. Nat Rev Cardiol 12:312-316

92. Lauer MS, D'Agostino RB Sr (2013) The randomized registry trialthe next disruptive technology in clinical research? N Engl J Med 369:1579-1581

93. Nichol G, Brown SP, Perkins GD et al (2016) What change in outcomes after cardiac arrest is necessary to change practice? Results of an international survey. Resuscitation 107:115-120

94. Booth CM, Eisenhauer EA (2012) Progression-free survival: meaningful or simply measurable? J Clin Oncol 30:1030-1033

95. Dancey JE, Dodd LE, Ford R et al (2009) Recommendations for the assessment of progression in randomised cancer treatment trials. Eur J Cancer 45:281-289
96. Gaudry S, Messika J, Ricard JD et al (2017) Patient-important outcomes in randomized controlled trials in critically ill patients: a systematic review. Ann Intensive Care 7:28

97. Haywood K, Whitehead L, Nadkarni VM et al (2018) COSCA (Core Outcome Set for Cardiac Arrest) in adults an advisory statement from the International Liaison Committee on resuscitation. Resuscitation 127:147-163

98. Ji C, Lall R, Quinn T et al (2017) Post-admission outcomes of participants in the PARAMEDIC trial: a cluster randomised trial of mechanical or manual chest compressions. Resuscitation 118:82-88

99. Agarwal S, Presciutti A, Roth W et al (2018) Determinants of long-term neurological recovery patterns relative to hospital discharge among cardiac arrest survivors. Crit Care Med 46:e141-e150

100. Grimshaw JM, Eccles MP, Lavis JN, Hill SJ, Squires JE (2012) Knowledge translation of research findings. Implement Sci 7:50

101. Perkins GD, Neumar R, Monsieurs KG et al (2017) The International Liaison Committee on resuscitation-review of the last 25 years and vision for the future. Resuscitation 121:104-116

102. Norton WE, McCannon CJ, Schall MW, Mittman BS (2012) A stakeholderdriven agenda for advancing the science and practice of scale-up and spread in health. Implement Sci 7:118 